\title{
Lumbar Muscle Fat Content Has More Correlations with Living Quality than Sagittal Vertical Axis in Elderly Patients with Degenerative Lumbar Disorders
}

This article was published in the following Dove Press journal:

Clinical Interventions in Aging

\author{
Weiguo Zhu ${ }^{1,2, *}$ \\ Wei Wang ${ }^{1,2, *}$ \\ Chao Kong ${ }^{1,2}$ \\ Yu Wang ${ }^{1,2}$ \\ Fumin Pan ${ }^{1,2}$ \\ Shibao Lu ${ }^{1,2}$ \\ 'Department of Orthopaedic Surgery, \\ Capital Medical University Xuanwu \\ Hospital, Beijing, People's Republic of \\ China; ${ }^{2}$ National Clinical Research \\ Center for Geriatric Diseases, Beijing, \\ People's Republic of China
}

*These authors contributed equally to this work
Correspondence: Shibao Lu

Department of Orthopaedic Surgery,

Capital Medical University Xuanwu

Hospital, Beijing 100053, People's

Republic of China

Email lushibaoxuanwu@163.com
Purpose: As the most poorly tolerated and debilitating form of spinal malalignment, sagittal imbalance is becoming an increasingly recognized cause of pain and disability in adults. However, there is evidence showing that sagittal imbalance has a weak or no correlation with health-related quality-of-life (HRQoL) outcomes. The objective of this study was to describe the direct factor associated with HRQoL in terms of Oswestry Disability Index (ODI) assessment.

Patients and Methods: This study retrospectively evaluated the clinical and radiographic information of 179 elderly patients with degenerative lumbar disorders and suboptimal sagittal standing posture (sagittal vertical axis $>50 \mathrm{~mm}$ ). Patient-reported outcomes were assessed using ODI. Patients with $\mathrm{ODI} \geq 40 \%$ were assigned to Group D (disability), while those with $\mathrm{ODI}<40 \%$ were assigned to Group ND (non-disability).

Results: Compared with Group ND ( $\mathrm{n}=104)$, patients in Group D $(\mathrm{n}=75)$ had greater thoracolumbar kyphosis, pelvic incidence-lumbar lordosis (PI-LL), sagittal vertical axis (SVA), T1 pelvic angle, and fat infiltration, and smaller LL and muscle mass ratio. Pearson analysis revealed a high correlation between the percentage of fat infiltrated and ODI $(\mathrm{r}=768, P<0.01)$ and moderate correlation between SVA and ODI $(\mathrm{r}=0.408, P<0.001)$. Linear regression results indicated that fat infiltration was an independent factor associated with ODI. ODI significantly correlated with SVA in patients with major fat infiltration (r=0.328, $P=0.001$ ), while having no correlation with SVA in those with moderate or minor fat infiltration $(\mathrm{r}=0.083, P=0.464)$.

Conclusion: Lumbar muscle fat infiltration is an independent factor associated with the living quality in terms of ODI assessment in the elderly population with degenerative lumbar disorders, which has more correlations with ODI scores than the sagittal imbalance. The relationship between HRQoL outcomes and sagittal imbalance depends on the quality of lumbar muscle.

Keywords: elderly patients, living quality, sagittal imbalance, lumbar muscle quality, degenerative lumbar disorders, correlation

\section{Introduction}

Sagittal imbalance, also known as sagittal plane malalignment, usually refers to the spinal deformity that results in forward postural instability, which is now most frequently defined by the position of $\mathrm{C} 7$ plumb line $>5 \mathrm{~cm}$ ventral to the posterosuperior margin of sacrum on standing lateral whole spine radiograph. ${ }^{1,2}$ As the most poorly tolerated and debilitating form of spinal malalignment, sagittal imbalance is becoming an increasingly recognized cause of pain and disability in adults. ${ }^{3}$ 
Previous studies have shown that increasing sagittal vertical axis (SVA) is associated with poor health-related quality-of-life (HRQoL) outcome. ${ }^{4,5}$ Therefore, taking this inability to stand upright into consideration is important when assessing the degree of spinal disorders.

However, recent studies do not always show a direct correlation between sagittal imbalance and living quality.-

${ }^{6,7}$ Faraj et $\mathrm{al}^{6}$ conducted a multicenter retrospective study including 74 patients with symptomatic de novo degenerative lumbar scoliosis to investigate the influence of sagittal radiographic parameters on preoperative HRQoL. They found a weak correlation between SVA and the Oswestry Disability Index (ODI) scores $(\mathrm{r}=0.296, \quad P<0.05)$. However, no significant correlation was found between SVA and other HRQoL questionnaire scores. Takemoto et $\mathrm{al}^{7}$ constructed multivariate linear regression models to evaluate the association between pre-operative ODI and sagittal parameters in 204 patients with adult spinal deformity (ASD). When adjusted for demographic and surgical variables, no correlation was observed between SVA and ODI scores. Another prospective radiographic study performed by Araújo et $\mathrm{al}^{8}$ even found that suboptimal sagittal standing posture had no significant impact on HRQoL in a sex-stratified general population (178 males and 311 females), when adjusted by age, education, and BMI.

Sagittal imbalance is common in the elderly population, which is mainly attributed to the degenerative changes including decreased lumbar lordosis (LL) and increased thoracic kyphosis (TK) in aging spine. ${ }^{9,10}$ In clinical practice, however, we also observe a weak correlation between the degenerative sagittal imbalance and quality-of-life in elderly patients that complain with worsening pain and fatigue with activities, while others do not have the same symptoms. Thus, we conducted this study with the following aims: 1) to compare the clinical and radiographic characteristics between elderly subjects with degenerative sagittal imbalance with different suboptimal health statuses, and 2) to describe the direct factor associated with HRQoL in terms of ODI assessment.

\section{Patients and Methods}

\section{Subjects}

Under the approval of the Ethics Committee of Capital Medical University Xuanwu Hospital, a retrospective analysis of clinical and radiographic information of elderly patients with suboptimal sagittal standing posture (SVA>50 mm) between September 2016 to September
2019 was performed. The following inclusion criteria were applied: 1) age $\geq 60$ years; 2) having primary sagittal imbalance; ${ }^{1}$ and 3) with complete radiologic images. Patients with non-degenerative spinal disorders (such as traumas, tumors, and inflammatory spinal arthropathies), hip pathology, and a history of spinal or pelvic surgery were excluded.

\section{Clinical and Radiographic Evaluation Clinical Evaluation}

Subjects' age, gender, body mass index (BMI), mean bone mineral density (BMD) of lumbar vertebra, and degenerative spinal disorders were recorded. Curve with a Cobb's angle in the coronal plain of more than 10 degrees was defined as scoliosis and kyphosis with a Cobb's angle in the lateral plain of more than 40 degrees was defined as hyperkyphosis. ${ }^{11,12}$ ODI scores $^{13}$ were collected at the time of radiographic acquisition.

\section{Spinopelvic Parameters}

Radiographic measurements were performed on long-cassette standing lateral radiographs of the spine and pelvis. ${ }^{14}$ The following radiographic parameters were measured using Surgimap software (Nemaris, Inc., New York, NY, USA):

1. TK, the angle between the superior end plate of T5 and the inferior endplate of T12.

2. Thoracolumbar kyphosis (TLK), the angle between the superior endplate of T10 and the inferior endplate of L2.

3. LL, the angle between the upper endplate of L1 and the superior endplate of S1.

4. Pelvic incidence (PI), the angle between the perpendicular to the superior endplate of S1 at its midpoint and the line connecting the point to the middle axis of the femoral heads.

5. Sacral slope (SS), the angle between the sacral plate and the horizontal plane.

6. Pelvic tilt (PT), the angle between the line connecting the midpoint of the superior endplate of S1 to the axis of the femoral heads, and the gravity line.

7. PI-LL mismatch equaled to PI minus LL.

8. Sagittal vertical axis (SVA), the horizontal distance between the $\mathrm{C} 7$ plumbline and the posterior-superior corner of the sacrum. Negative values of SVA indicated that the $\mathrm{C} 7$ plumbline fell behind the sacrum. 
9. T1 pelvic angle (TPA), the angle subtended by a line from the femoral heads to the center of the $\mathrm{T} 1$ vertebral body, and a line from the femoral heads to the midpoint of the superior endplate of $\mathrm{S} 1 .{ }^{15}$ Negative values indicated that the line from the femoral heads to the center of the T1 was placed behind the line from the femoral heads to the center of the superior sacral end plate.

\section{Disk Degeneration}

The degree of disk degeneration (L1-L2 to L5-S1) was examined on 1.5T MRI (Siemens, Erlangen, Germany) images using Pfirrmann disk degeneration classification. ${ }^{16}$ Five grades were comprised on sagittal T2-weighted images, representing a progression from normal disk to severe disk degeneration. Grade I corresponded to no degeneration, whereas grade $\mathrm{V}$ represented most severe degeneration. Scoring was calculated for convenient assessment, to grade I a score of 5 score, whereas to grade $\mathrm{V}$ a score of 1given. Higher scores represented better disk conditions. The average value of the five scores was calculated.

\section{Facet Joint Degeneration}

The degree of right facet joint osteoarthritis (FJ OA) (L1L2 to L5-S1) was evaluated on CT images according to previous studies. ${ }^{17,18}$ Four grades of FJ OA were defined: Grade 0 represented no degeneration, whereas grade III represented severe degeneration. Scoring was calculated for convenient assessment, to grade 0 a score of 4 was given, whereas to grade III a score of 1 was given. Higher scores represented better facet joint conditions. The average value of the five scores was calculated.

\section{Back Muscle Degeneration}

The cross-sectional area (CSA) of lumbar paravertebral muscle was assessed on 1.5T MRI (Siemens, Erlangen, Germany) images utilizing Picture Archiving and Communication System (PACS). ${ }^{19,20}$ The condition of MRI scan was as follows: matrix size $=320 \times 320$, slice thickness $=4.0 \mathrm{~mm}$, slice per $\mathrm{slab}=15$, number of excitations $=2$. T2-weighted axial images of the L1-2, L2-3, L34 , and L4-5 intervertebral disc levels were used to analyze the right muscle size and morphology. The regions of interest (ROI) of back muscle were determined by outlining the fascial boundary of the muscles (the fascia thoracolumbalis was traced down laterally and anteriorly to the dorsal side of the quadratus lumborum, followed by the posterior surface of the facet and lamina, and lateral margin of the spinous process) (Figure 1A). ${ }^{19}$ The signal intensity (in gray scale) of the muscle within the ROI was measured using the measurement function of PACS. The percentage of fat infiltrated area was measured using a pseudocoloring technique (threshold technique) (Figure 1C). In order to decrease the bias caused by body size, the area of back muscle was divided by the disc area of the same level (muscle-disc ratio) (Figure 1B). ${ }^{19}$ Mean values of muscle mass and fat infiltration of the four levels were calculated.

All the radiographic data were collected by two independent spine surgeons, who were not involved in the treatment of the patients. The mean values were recorded.

\section{Groups}

All the patients were divided into two groups based on the value of 40 points according to the ODI score. ${ }^{13,21}$ Patients with ODI score $\geq 40 \%$ were assigned to the relative disability group (Group D), and those with ODI score $<40 \%$ were assigned to the relative non-disability group (Group ND).

\section{Statistical Analysis}

Values were expressed as mean \pm standard deviation. The intra- and inter-observer reliabilities of the measurement of muscle fat infiltration were analyzed using intra-class correlations (ICC). Chi-square analysis was used for comparisons of categorical variables between groups. Comparisons of continuous variables were performed with independent-samples $t$-test. Correlations between the selected variables from univariate analysis and ODI scores were evaluated. Based on the correlation results, linear regression analysis was performed to identify the factors independently associated with ODI scores. All statistical analyses were performed with SPSS version 19.0 (SPSS Inc, Chicago, IL), and a $P$-value $<0.05$ was considered significant.

\section{Results}

\section{Intra- and Interobserver Reliability Analysis}

The measurement of muscle fat infiltration had good agreement, with substantial intra- and interobserver reliabilities. The intra- and inter-observer ICC for the measurement was 0.896 (95\% confidence interval $=0.793-$ $0.950)$ and $0.852(95 \%$ confidence interval $=0.736-0.934)$, respectively. 


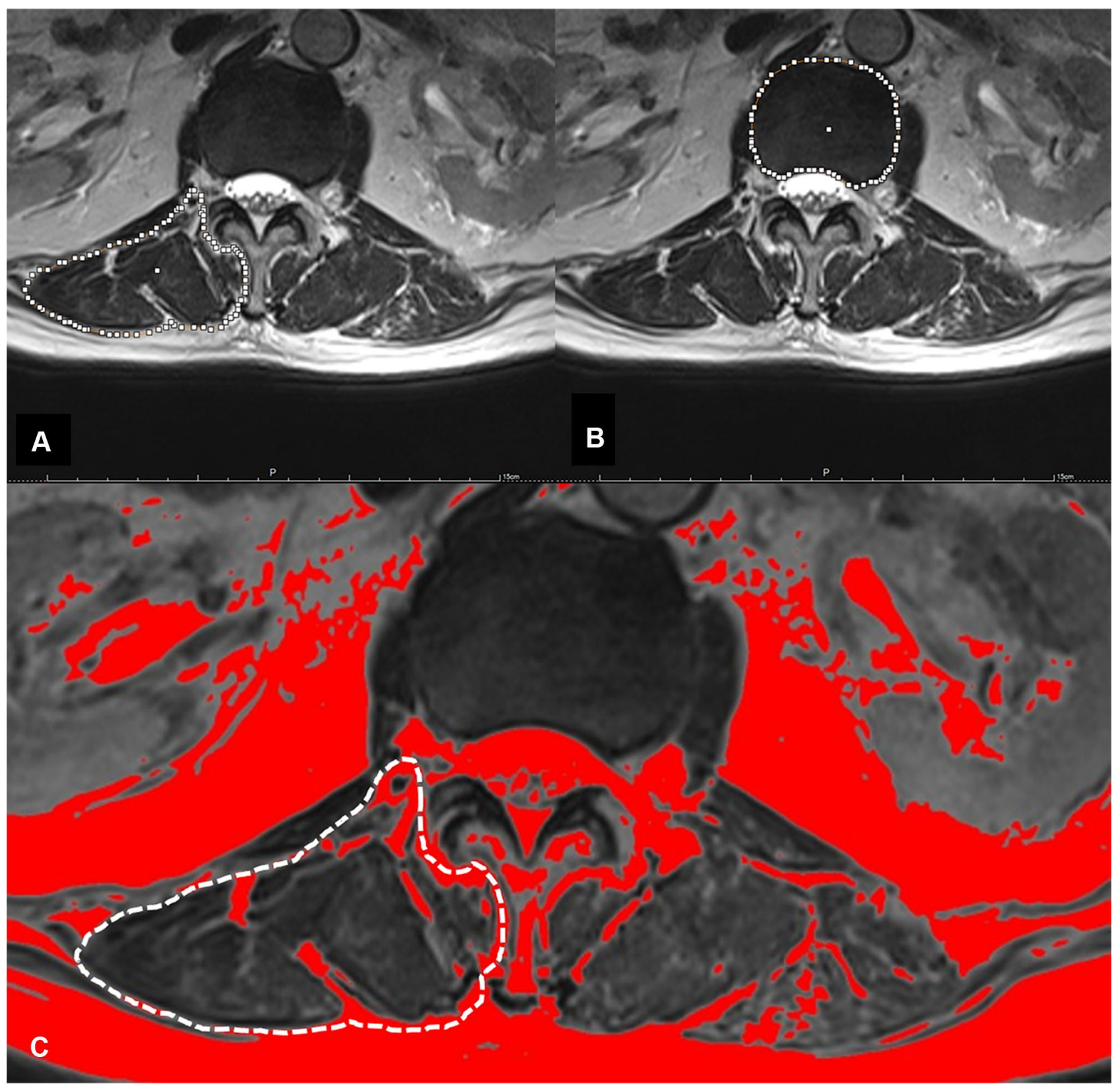

Figure I (A) The fascial boundary of lumbar paravertebral muscles (white circle). (B) The boundary of vertebral body (white circle). Muscle-disc ratio was (muscle area)/ (disc area): $19.53 / 16.30=1.20$. (C) Bright pixels of fat tissue in the MR images were colored in red (darker color in the black and white version) using pseudocoloring technique (threshold technique). The percentage of the red pixel area in the white circle was calculated (I4.21\%).

Demographic Data of the Whole Cohort A total of 179 subjects ( 78 males and 101 females) were included in this study, with an average age of $70.8 \pm 7.7$ years, an average BMI of $26.1 \pm 1.4 \mathrm{~kg} / \mathrm{m}^{2}$ and an average BMD of $1.063 \pm 0.121 \mathrm{~g} / \mathrm{cm}^{2}$. One hundred and thirteen subjects were identified with lumbar disc herniation (1 level: 42, 2 levels: 48, 3 levels: 22, 4 levels: 1), 44 subjects were identified with lumbar spondylolisthesis (1 level: 42 , 2 levels: 2), 51 subjects were identified with degenerative scoliosis, and 21 subjects were identified with hyperkyphosis.

\section{Comparisons of Demographic and} Radiologic Data Between Groups D and ND Seventy-five patients with ODI scores $>40 \%$ were assigned to Group D, and the others with ODI score $\leq 40 \%$ were assigned to Group ND. As shown in Table 1, patients in the two groups were comparable in age, gender 
Table I Comparisons of Demographic Data Between Group D and Group ND

\begin{tabular}{|c|c|c|c|}
\hline Characteristics & $\begin{array}{l}\text { Group D } \\
(n=75)\end{array}$ & $\begin{array}{l}\text { Group ND } \\
(n=104)\end{array}$ & $P$ \\
\hline Mean age (years) & $72.2 \pm 7.4$ & $69.7 \pm 8.1$ & 0.217 \\
\hline Gender (M/F) & $30 / 45$ & $48 / 56$ & $0.413^{\dagger}$ \\
\hline Body mass index $\left(\mathrm{kg} / \mathrm{m}^{2}\right)$ & $25.7 \pm 1.3$ & $26.4 \pm 1.5$ & 0.712 \\
\hline Bone mineral density $\left(\mathrm{g} / \mathrm{cm}^{2}\right)$ & $1.012 \pm 0.139$ & $1.095 \pm 0.115$ & 0.508 \\
\hline \multicolumn{4}{|l|}{ Degenerative lumbar disorders } \\
\hline \multirow[t]{4}{*}{ Disc herniation } & I level: I7 & I level: 25 & $0.736^{\dagger}$ \\
\hline & 2 levels: 20 & 2 levels: 28 & \\
\hline & 3 levels: 9 & 3 levels: 13 & \\
\hline & 4 levels: 0 & 4 levels: I & \\
\hline \multirow[t]{2}{*}{ Spondylolisthesis } & I level: 12 & I level: 30 & $0.265^{\dagger}$ \\
\hline & 2 levels: 0 & 2 levels: 2 & \\
\hline Scoliosis & 18 & 33 & $0.635^{\dagger}$ \\
\hline Hyperkyphosis & 14 & 7 & $0.014^{\dagger}$ \\
\hline
\end{tabular}

Notes: Group $D$ indicates the group including patients with ODI score $\geq 40$ points; Group ND, the group including patients with ODI score $<40$ points. ${ }^{\dagger}$ Calculated by Chi-square analysis.

distribution, BMI, and BMD. More patients had hyperkyphosis in Group D than Group ND (18.7\% vs 6.7\%, $P=0.014)$. The distributions of diagnoses of lumbar disc herniation, spondylolisthesis, and scoliosis were similar between the two groups.

Compared with Group ND, patients in Group D had greater TLK $\left(28.0 \pm 10.1^{\circ}\right.$ vs $\left.14.4 \pm 11.2^{\circ}, P=0.017\right)$, PI-LL
(16.3 $\pm 4.4^{\circ}$ vs $\left.7.5 \pm 3.6^{\circ}, P<0.001\right)$, SVA $(116.3 \pm 26.8 \mathrm{~mm}$ vs $86.5 \pm 16.5 \mathrm{~mm}, P=0.008)$, and TPA $\left(22.3 \pm 12.3^{\circ}\right.$ vs 17.5 $\left.\pm 8.8^{\circ}, P=0.030\right)$ and smaller LL $\left(30.6 \pm 14.2^{\circ}\right.$ vs 42.3 $\left.\pm 8.8^{\circ}, P=0.014\right)$. Assessments of lumbar disc and facet degeneration did not show significant differences between the two groups. With respect to back muscle, patients with ODI $>40 \%$ had a smaller muscle mass ratio ( $1.15 \pm 0.32$ vs $1.42 \pm 0.35, P=0.022$ ) and a larger percentage of fat infiltrated $(40.4 \pm 5.0 \%$ vs $25.8 \pm 4.3 \%, P<0.001)$ than those with ODI $\leq 40 \%$ (Table 2).

\section{Correlation and Regression Analyses in the Whole Cohort}

The univariate analysis showed that TLK, LL, PI-LL, SVA, TPA, muscle-disc ratio, and percentage of fat infiltrated might be the associated factors with ODI score. Correlation analyses between these selected variables and ODI score were then performed. Results revealed a high correlation between muscle fat infiltration and ODI $(\mathrm{r}=768, P<0.01)$ and a moderate correlation between SVA and ODI $(\mathrm{r}=0.408, P<0.001)$ (Table 3$)$. Significant correlations were not found between other radiologic parameters and ODI assessment. Scatterplots for the relationship of ODI with percentage of fat infiltrated and SVA are shown in Figure 2A and B. Linear regression analysis further indicated that muscle fat infiltration was an independent factor associated with ODI (Table 4).

Table 2 Comparisons of Radiographic Assessments Between Group D and Group ND

\begin{tabular}{|c|c|c|c|}
\hline Characteristics & $\begin{array}{l}\text { Group D } \\
(n=75)\end{array}$ & $\begin{array}{l}\text { Group ND } \\
(n=104)\end{array}$ & $P$ \\
\hline \multicolumn{4}{|l|}{ Spinopelvic parameters } \\
\hline Thoracic kyphosis $\left({ }^{\circ}\right)$ & $29.9 \pm 9.3$ & $27.7 \pm 8.0$ & 0.612 \\
\hline Thoracolumbar kyphosis $\left({ }^{\circ}\right)$ & $28.0 \pm 10.1$ & $|4.4 \pm| \mid .2$ & 0.017 \\
\hline Lumbar lordosis $\left({ }^{\circ}\right)$ & $30.6 \pm 14.2$ & $42.3 \pm 8.8$ & 0.014 \\
\hline Pelvic incidence $\left({ }^{\circ}\right)$ & $46.4 \pm 9.1$ & $49.0 \pm 9.8$ & 0.206 \\
\hline Pelvic tilt $\left({ }^{\circ}\right)$ & $18.7 \pm 8.6$ & $14.3 \pm .7$ & 0.107 \\
\hline Sacral slope $\left({ }^{\circ}\right)$ & $28.5 \pm 14.9$ & $34.6 \pm 12.9$ & 0.081 \\
\hline Pelvic incidence minus lumbar lordosis $\left({ }^{\circ}\right)$ & $16.3 \pm 4.4$ & $7.5 \pm 3.6$ & $<0.001$ \\
\hline Sagittal vertical axis $(\mathrm{mm})$ & $116.3 \pm 26.8$ & $86.5 \pm 16.5$ & 0.008 \\
\hline TI pelvic angle $\left({ }^{\circ}\right)$ & $22.3 \pm 12.3$ & $17.5 \pm 8.8$ & 0.030 \\
\hline Disk degeneration & $3.45 \pm 1.02$ & $3.6 \mathrm{I} \pm 0.99$ & 0.311 \\
\hline Facet degeneration & $2.48 \pm 0.55$ & $2.39 \pm 0.62$ & $0.44 I$ \\
\hline \multicolumn{4}{|l|}{ Paravertebral muscle degeneration } \\
\hline Muscle-disc ratio & $1.15 \pm 0.32$ & $1.42 \pm 0.35$ & 0.022 \\
\hline Percentage of fat infiltrated (\%) & $40.4 \pm 5.0$ & $25.8 \pm 4.3$ & $<0.001$ \\
\hline
\end{tabular}

Notes: Group D indicates the group including patients with ODI score $\geq 40$ points; Group ND, the group including patients with $O D I$ score $<40$ points. 
Table 3 The Correlations Between the Selected Radiologic Parameters and ODI Score in the Whole Cohort

\begin{tabular}{|l|l|l|l|l|l|l|l|l|}
\hline & & TLK & LL & PI-LL & SVA & TPA & MDR & FI \\
\hline ODI score & $\mathrm{r}$ & 0.133 & -0.160 & 0.195 & 0.408 & 0.201 & 0.191 & 0.768 \\
& $P$ & 0.327 & 0.212 & 0.102 & $<0.001$ & 0.088 & 0.116 & $<0.001$ \\
\hline
\end{tabular}

Abbreviations: TLK, thoracolumbar kyphosis; LL, lumbar lordosis; PI-LL, pelvic incidence minus LL; SVA, sagittal vertical axis; TPA, TI pelvic angle; MDR, muscle-disc ratio; $\mathrm{Fl}$, percentage of fat infiltrated.

\section{Correlations Between SVA and ODI in Patients with Major or Moderate Muscle Fat Infiltration}

According to the result that muscle fat infiltration was the independent factor associated with ODI, patients were divided into two groups based on the mean percentage of fat infiltrated $(33.6 \pm 12.3 \%)$. Correlations between SVA and ODI were respectively analyzed in patients with major $(>33 \%)$ and moderate $(\leq 33 \%)$ muscle fat infiltration. Results showed that SVA was significantly correlated with ODI in patients with major fat infiltration $(r=0.328$,
$P=0.001)$, while not correlated in those with moderate fat infiltration $(\mathrm{r}=0.083, P=0.464)$ (Figure $2 \mathrm{C}$ and $\mathrm{D})$.

\section{Discussions}

Ideal spinal alignment allows an individual to assume an upright posture with minimal muscular energy expenditure. Positive spinal sagittal imbalance would increase the trunk muscular effort and energy expenditure to maintain a standing position, which then gradually results in low back pain, fatigue, and disability. ${ }^{22}$ Numerous studies have reported a relationship between the area or fat infiltration

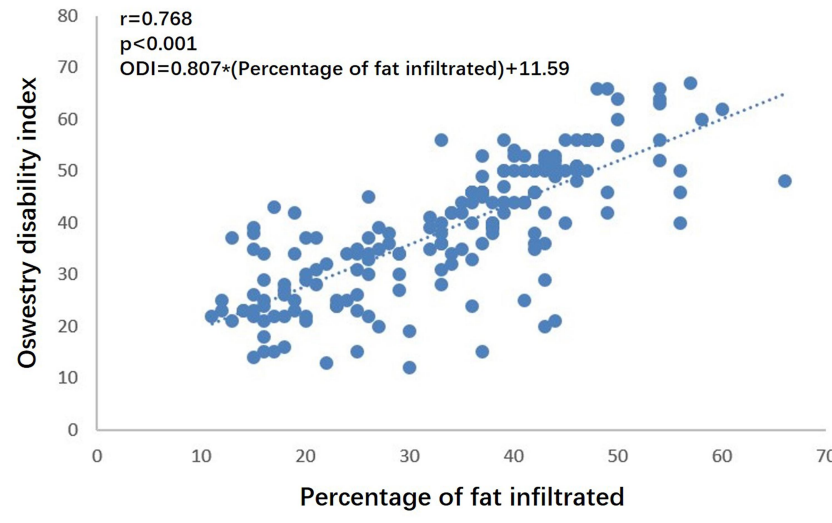

A

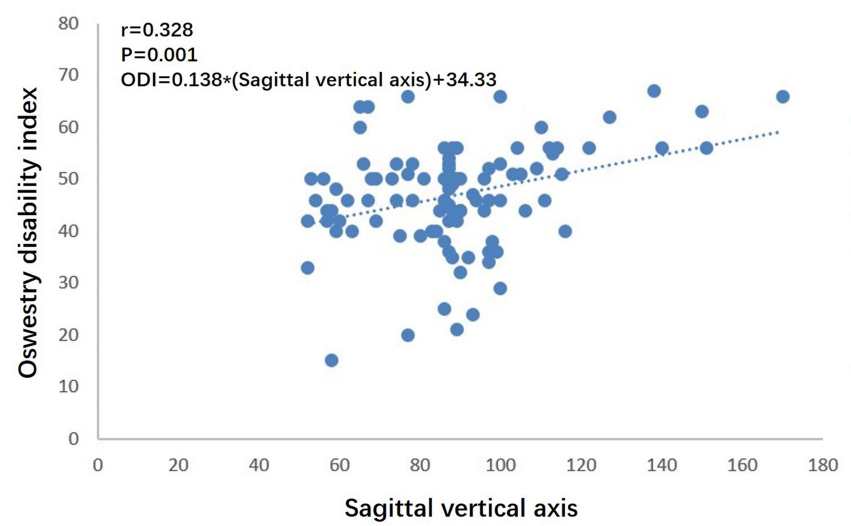

C

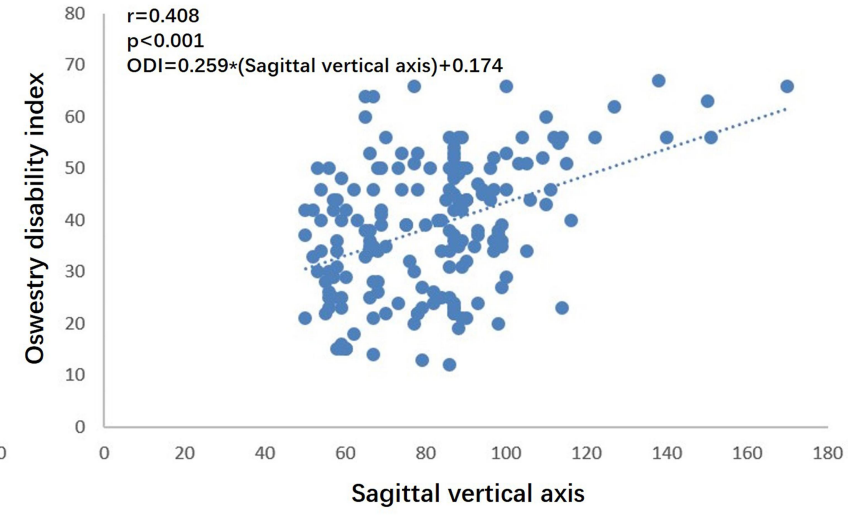

B

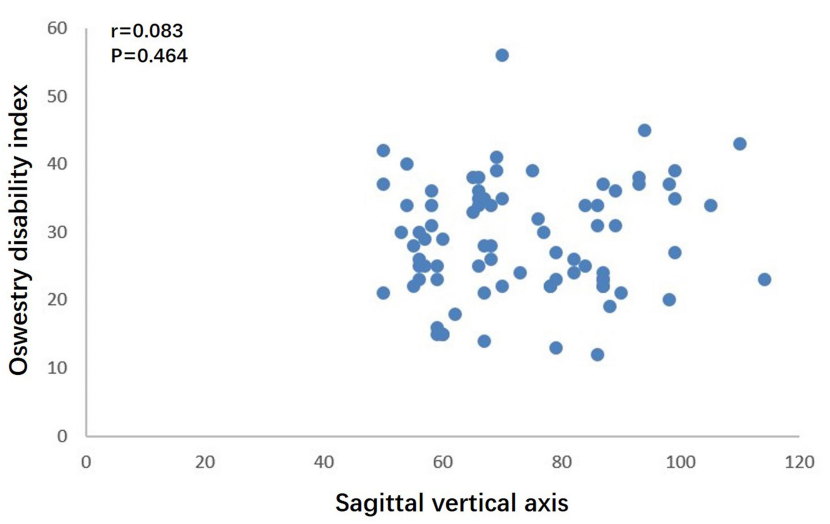

D

Figure 2 Scatterplots for the relationships of ODI with percentage of fat infiltrated and SVA. In the whole cohort of patients with degenerative lumbar disorders, ODI was strongly correlated with the percentage of fat infiltrated (A) and SVA (B). The association between SVA and quality-of-life depends on the quality of paravertebral muscle. ODI was moderately correlated with SVA in patients with major fat infiltration (>33\%) of lumbar muscle (C), while not correlated with SVA in patients with moderate or minor fat infiltration ( $\leq 33 \%$ ) of lumbar muscle (D). 
Table 4 Linear Regression Analysis for ODI with Percentage of Fat Infiltrated and SVA

\begin{tabular}{|l|l|l|l|l|l|}
\hline Groups & Variables & $\mathbf{R}^{\mathbf{2}}$ & Unstandardized Coefficients & Standardized Coefficients & $\boldsymbol{P}$ \\
\hline Whole cohort & Percentage of fat infiltrated & 0.594 & 0.770 & 0.732 & $<0.001$ \\
& Sagittal vertical axis & & 0.047 & 0.076 & 0.164 \\
\hline
\end{tabular}

of trunk muscle (especially the paravertebral muscle) and low back pain. ${ }^{23}$ Using CT imaging, Danneels et $\mathrm{al}^{23}$ demonstrated the cross-sectional area of the multifidus at L4 level was statistically smaller in 32 patients with low back pain than the 23 healthy controls. Hebert et al ${ }^{24}$ found 401 subjects who were 40-year-old with severe lumbar multifidus fat infiltration had increased odds of ever experiencing low back pain in the past year. In a community-based MRI cohort study including 72 adults with low back pain, a high percentage of fat in the multifidus was associated with an increased risk of high-intensity pain. ${ }^{25}$ Although it was hard to determine whether structural abnormalities of the back muscle were a cause or result of low back pain, they thought the muscular atrophy and fat infiltration could permit spinal instability which was an important factor contributing to the occurrence of low back pain.

Low back pain is considered as one of the critical factors jeopardizing healthy life expectancy and a leading cause of years lived with disability. ${ }^{26,27}$ Despite paraspinal muscle degeneration has been recognized as a risk factor of low back pain, there is still a rare study on the relationship of paravertebral muscle with quality-of-life. Recently, Hori et $\mathrm{a}^{28}$ performed a multicenter cross-sectional study to clarify the relationship of trunk muscle mass with low back pain, spinal sagittal balance, and quality-of-life by bioelectrical impedance analysis (BIA) method. Trunk muscles (including the iliopsoas and paravertebral muscles) mass was found to be significantly associated with the ODI, VAS score, SVA, and EQ5D score. In order to identify factors of suboptimal health status and optimize clinical decision-making, we compared the demographic and radiographic characteristics between elderly subjects with degenerative sagittal imbalance and different statuses of living disability. Patients with ODI $>40 \%$ were found with greater TLK, SVA, TPA, and percentage of fat infiltrated and smaller LL and muscle mass ratio than those with $\mathrm{ODI} \leq 40 \%$ (Table 2). Pearson analysis revealed that ODI scores were highly correlated with the percentage of fat infiltrated $(\mathrm{r}=768, P<0.01)$, while moderately correlated with SVA $(\mathrm{r}=0.408, P<0.001)$. Linear regression results further indicated that only muscle fat infiltration was the independent factor associated with ODI. Sagittal spinal alignment and balance have also been proven to be related to CSA and fat infiltration of paravertebral muscles. ${ }^{29,30} \mathrm{In}$ this regard, decreased living quality and sagittal malalignment could be deemed as two different manifestations of the poor back muscle status in the elderly. Therefore, it is reasonable that muscle fat content had more correlations with disability than sagittal imbalance in this study.

Spinal sagittal imbalance is traditionally considered as a common cause of living disability. Recent evidences indicated that sagittal imbalance might not necessarily be associated with quality-of-life. ${ }^{6-8}$ In their study, HRQoL questionnaire scores were shown to have a weak or no correlation with SVA in patients with ASD and even in the general population, when adjusted for demographic variables. We speculated that the paravertebral muscle disturbed the relationship of SVA and ODI. A good quality of muscle has the power to compensate for the sagittal imbalance, with minor symptoms. In contrast, a poor quality of muscle would cause major symptoms under moderate sagittal imbalance. In this regard, the association between sagittal imbalance and quality-of-life depends on the quality of paravertebral muscle (Figure 3A-D). Our study confirmed this theory that ODI was significantly correlated with SVA in patients with major fat infiltration $(\mathrm{r}=0.328, P=0.001)$, while not correlated with SVA in those with moderate or minor fat infiltration $(\mathrm{r}=0.083$, $P=0.464$ ). To our best knowledge, this result had never been reported before.

With regard to the associated factors with quality-oflife, most studies paid attention to the spinal sagittal malalignment and imbalance. To date, a rare study focused on the paravertebral muscle in the management of living disability in the elderly. The present study first found back muscular fat infiltration had more significant correlations with living quality than sagittal imbalance in an elderly population with degenerative lumbar disorders. Our results suggested paraspinal muscles should be taken into consideration when evaluating sagittal imbalance disorders and performing the correction surgery. 


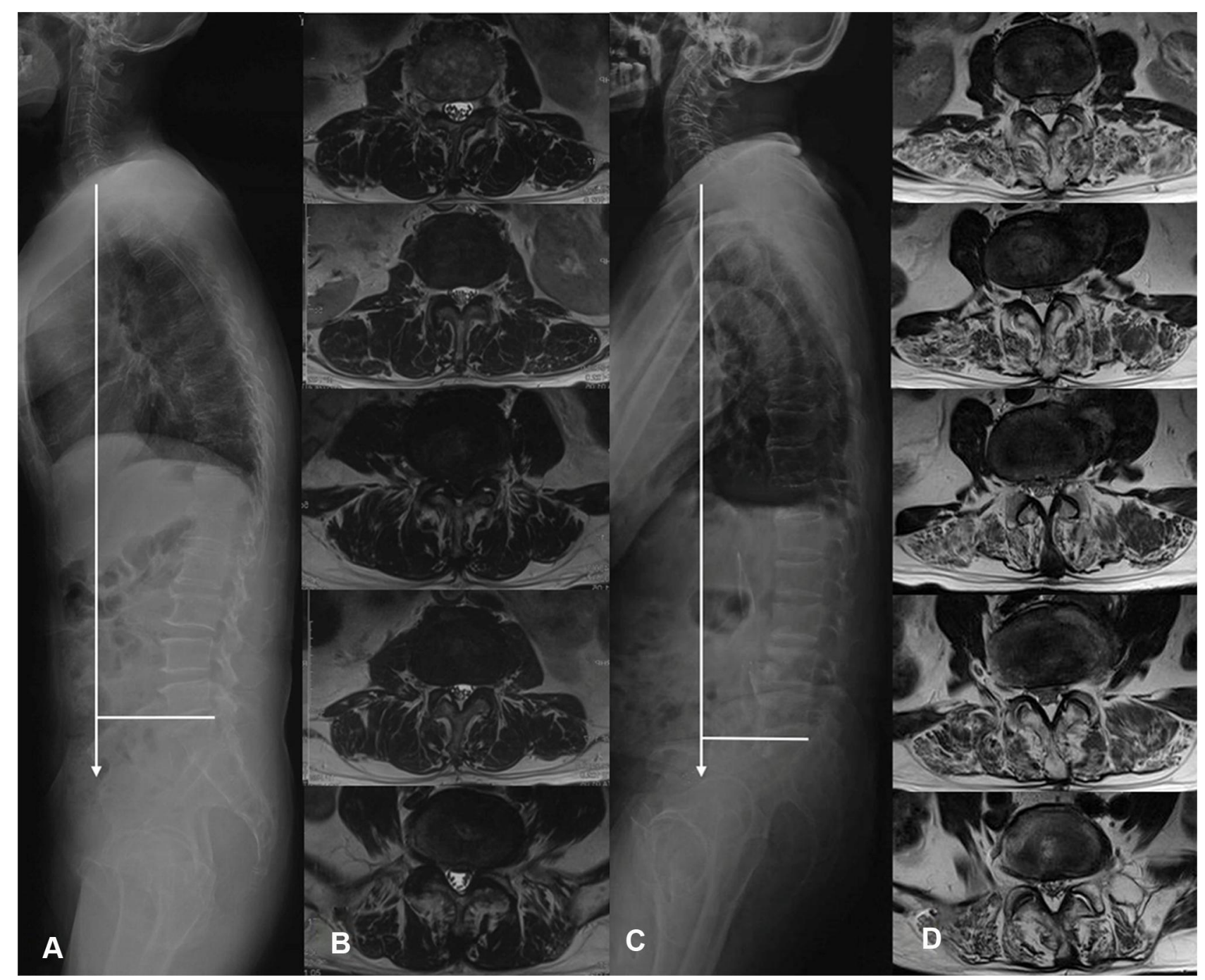

Figure 3 A 68-year-old male with an SVA of $88.5 \mathrm{~mm}(\mathbf{A})$ and a mean percentage of lumbar muscle fat infiltration of I6.3\% (B). His ODI score was $24 \%$. Another 66-year-old male with an SVA of $75.7 \mathrm{~mm}$ (C) and a mean percentage of lumbar muscle fat infiltration of $48.4 \%$ (D). His ODI score was $46 \%$.

This study has several limitations. First, this research was a cross-sectional study, which could not prove the causal relationship. We had no idea whether paraspinal muscle degeneration was the "cause" of spinal sagittal imbalance or the "result" of spinal sagittal imbalance. Second, SVA might be underestimated because of the compensatory mechanism of knee flexion. However, knee flexion could only be evaluated on the full-length radiographs. Third, subjects included were patients who needed an operation in our center, who could not represent the general population. Fourth, muscle strength is also associated with the low back pain and the quality-of-life in patients with lumbar degenerative changes. However, back muscle strength has not been assessed at our center. In spite of this, our results could also clarify the importance of paravertebral muscles in the management of spinal disorders with sagittal imbalance.

\section{Conclusion}

Lumbar muscle fat infiltration is an independent factor associated with the living quality in terms of ODI assessment in the elderly population with degenerative lumbar disorders, which has more correlations with ODI scores than the sagittal imbalance. The relationship between quality-of-life and sagittal imbalance depends on the lumbar muscle status. ODI evaluation is correlated with SVA in elderly subjects with major fat infiltration, while it is not correlated with SVA in those with moderate or minor fat infiltration. 


\section{Ethics Statement}

Patient consent to review their medical records was waived in the present study. The procedure performed in this study involving human participants was in accordance with the ethical standards of the Ethics Committee of Capital Medical University Xuanwu Hospital and/or the national research committee and with the 1964 Helsinki Declaration and its later amendments or comparable ethical standards.

\section{Funding}

This work was supported by National Natural Science Foundation of China (Grant No. 81,672,201), Project funded by China Postdoctoral Science Foundation and Beijing Postdoctoral working Fund.

\section{Disclosure}

The authors have no conflicts of interest to declare for this work.

\section{References}

1. Angevine PD, Bridwell KH. Sagittal imbalance. Neurosurg Clin N Am. 2006;17(3):353-363. doi:10.1016/j.nec.2006.04.005

2. Bridwell K. Causes of sagittal spinal imbalance and assessment of the extent of needed correction. Instr Course Lect. 2006;55:567-575.

3. Joseph SA, Moreno AP, Brandoff J, Casden AC, Kuflik P, Neuwirth MG. Sagittal plane deformity in the adult patient. $J$ Am Acad Orthop Surg. 2009;17(6):378-388. doi:10.5435/00124635-200906000-00006

4. Glassman SD, Bridwell K, Dimar JR, Horton W, Berven S, Schwab F. The impact of positive sagittal balance in adult spinal deformity. Spine (Phila Pa 1976). 2005;30(18):2024-2029. doi:10.1097/01. brs.0000179086.30449.96

5. Glassman SD, Berven S, Bridwell K, Horton W, Dimar JR. Correlation of radiographic parameters and clinical symptoms in adult scoliosis. Spine. 2005;30(6):682-688. doi:10.1097/01. brs.0000155425.04536.f7

6. Faraj SSA, De Kleuver M, Vila-Casademunt A, et al. Sagittal radiographic parameters demonstrate weak correlations with pretreatment patient-reported health-related quality of life measures in symptomatic de novo degenerative lumbar scoliosis: a European multicenter analysis. J Neurosurg Spine. 2018;28(6):573-580. doi:10.3171/ 2017.8.SPINE161266

7. Takemoto M, Boissière L, Vital JM, et al. Are sagittal spinopelvic radiographic parameters significantly associated with quality of life of adult spinal deformity patients? Multivariate linear regression analyses for preoperative and short-term post-operative health-related quality of life. Eur Spine J. 2017;26(8):2176-2186. doi:10.1007/s00586-016-4872-y

8. Araújo F, Lucas R, Alegrete N, Azevedo A, Barros H. Sagittal standing posture, back pain, and quality of life among adults from the general population: a sex-specific association. Spine (Phila Pa 1976). 2014;39(13):E782-794. doi:10.1097/BRS.0000000000000347

9. Sparrey CJ, Bailey JF, Safaee M, et al. Etiology of lumbar lordosis and its pathophysiology: a review of the evolution of lumbar lordosis, and the mechanics and biology of lumbar degeneration. Neurosurg Focus. 2014;36(5):E1. doi:10.3171/2014.1.FOCUS13551

10. Lee $\mathrm{CH}$, Chung CK, Jang JS, et al. Effectiveness of deformitycorrection surgery for primary degenerative sagittal imbalance: a meta-analysis. J Neurosurg Spine. 2017;27(5):540. doi:10.3171/ 2017.3.SPINE161134
11. Max A. The adult scoliosis. Eur Spine J. 2005;14(10):925-948. doi:10.1007/s00586-005-1053-9

12. Katzman WB, Wanek L, Shepherd JA, Sellmeyer DE. Age-related hyperkyphosis: its causes, consequences, and management. $J$ Orthop Sports Phys Ther. 2010;40(6):352-360. doi:10.2519/ jospt.2010.3099

13. Fairbank JCT, Pynsent PB. The oswestry disability index. Spine. 2000;25(22):2940-2953. doi:10.1097/00007632-2000111 50-00017

14. Feng Z, Hongda B, Shouyu H, et al. Lumbo-femoral angle: a novel sagittal parameter related to quality of life in patients with adult scoliosis. Eur Spine J. 2015;24(6):1244-1250. doi:10.1007/s00586-014-3614-2

15. Themistocles P, Frank S, Nicolas B, et al. The T1 pelvic angle, a novel radiographic measure of global sagittal deformity, accounts for both spinal inclination and pelvic tilt and correlates with healthrelated quality of life. J Bone Joint Surg Am. 2014;96(19):16311640. doi:10.2106/JBJS.M.01459

16. Pfirrmann CW, Metzdorf A, Zanetti M, Hodler J, Boos N. Magnetic resonance classification of lumbar intervertebral disc degeneration. Spine. 2001;26(17):1873-1878. doi:10.1097/00007632-20010901000011

17. Weishaupt D, Zanetti M, Boos N, Hodler J. MR imaging and CT in osteoarthritis of the lumbar facet joints. Skeletal Radiol. 1999;28 (4):215-219. doi:10.1007/s002560050503

18. Kalichman L, Li L, Dh GA, et al. Facet joint osteoarthritis and low back pain in the community-based population. Spine. 2008;33 (23):2560-2565. doi:10.1097/BRS.0b013e318184ef95

19. Lee JC, Cha JG, Kim Y, Kim YI, Shin BJ. Quantitative analysis of back muscle degeneration in the patients with the degenerative lumbar flat back using a digital image analysis: comparison with the normal controls. Spine (Phila Pa 1976). 2008;33(3):318-325. doi:10.1097/BRS.0b013e318162458f

20. Chang MY, Park Y, Ha JW, et al. Paraspinal lean muscle mass measurement using spine MRI as a predictor of adjacent segment disease after lumbar fusion: a propensity score-matched case-control analysis. AJR Am J Roentgenol. 2019;1-8. doi:10.2214/AJR.18.20441.

21. Sanderson PL, Todd BD, Holt GR, Getty CJM. Compensation, work status, and disability in low back pain patients. Spine. 1995;20 (5):554-556. doi:10.1097/00007632-199503010-00009

22. Frank S, Ashish P, Benjamin U, Jean-Pierre F, Virginie L. Adult spinal deformity-postoperative standing imbalance: how much can you tolerate? An overview of key parameters in assessing alignment and planning corrective surgery. Spine. 2010;35(25):2224. doi:10.1097/BRS.0b013e3181ee6bd4

23. Danneels LA, Vanderstraeten GG, Cambier DC, Witvrouw EE, De Cuyper HJ, Danneels L. CT imaging of trunk muscles in chronic low back pain patients and healthy control subjects. Eur Spine J. 2000;9 (4):266-272. doi:10.1007/s005860000190

24. Hebert JJ, Kjaer P, Fritz JM, Walker BF. The relationship of lumbar multifidus muscle morphology to previous, current, and future low back pain: a 9-year population-based prospective cohort study. Spine (Phila Pa 1976). 2014;39(17):1417-1425. doi:10.1097/BRS.000000 0000000424

25. Teichtahl AJ, Urquhart DM, Wang Y, et al. Fat infiltration of paraspinal muscles is associated with low back pain, disability, and structural abnormalities in community-based adults. Spine J. 2015;15(7):1593-1601. doi:10.1016/j.spinee.2015.03.039

26. Vos T, Flaxman AD, Naghavi M, et al. Years lived with disability (YLDs) for 1160 sequelae of 289 diseases and injuries 1990-2010: a systematic analysis for the Global Burden of Disease Study 2010. Lancet. 2012;380(9859):2163-2196. doi:10.1016/S0140-6736(12) 61729-2

27. Hurwitz EL, Randhawa K, Yu H, Côté P, Haldeman S. The Global Spine Care Initiative: a summary of the global burden of low back and neck pain studies. Eur Spine J. 2018;27(Suppl 6):796-801. doi:10.1007/s00586017-5432-9 
28. Hori Y, Hoshino $\mathrm{M}$, Inage $\mathrm{K}$, et al. ISSLS PRIZE IN CLINICAL SCIENCE 2019: clinical importance of trunk muscle mass for low back pain, spinal balance, and quality of life - a multicenter cross-sectional study. Eur Spine J. 2019;28(Suppl1):914-921. doi:10.1007/s00586-01905904-7

29. Yagi M, Hosogane N, Watanabe K, Asazuma T, Matsumoto M. The paravertebral muscle and psoas for the maintenance of global spinal alignment in patient with degenerative lumbar scoliosis. Spine J. 2016;16(4):451-458. doi:10.1016/j.spinee.2015.07.001
30. Jun HS, Kim JH, Ahn JH, et al. The effect of lumbar spinal muscle on spinal sagittal alignment: evaluating muscle quantity and quality. Neurosurgery. 2016;79(6):847-855. doi:10.1227/NEU.0000000000 001269

\section{Publish your work in this journal}

Clinical Interventions in Aging is an international, peer-reviewed journal focusing on evidence-based reports on the value or lack thereof of treatments intended to prevent or delay the onset of maladaptive correlates of aging in human beings. This journal is indexed on PubMed Central, MedLine, CAS, Scopus and the Elsevier
Bibliographic databases. The manuscript management system is completely online and includes a very quick and fair peer-review system, which is all easy to use. Visit http://www.dovepress.com testimonials.php to read real quotes from published authors. 